\title{
CARACTERÍSTICAS FÍSICO-QUÍMICAS E PRODUTIVIDADE DE ACESSOS DE Passiflora nitida Kunth PROCEDENTES DO CENTRO-NORTE DO BRASIL ${ }^{1}$
}

\author{
NILTON TADEU VILELA JUNQUEIRA ${ }^{2}$, ERIVANDA CARVALHO DOS SANTOS ${ }^{2}$, \\ KEIZE PEREIRA JUNQUEIRA ${ }^{2}$, FÁBIO GELAPE FALEIRO ${ }^{2}$, \\ GRACIELE BELLON ${ }^{2}$, MARCELO FIDELES BRAGA ${ }^{2}$
}

RESUMO - O maracujá-suspiro (Passiflora nitida Kunth) é uma espécie silvestre amplamente distribuída no território nacional. Tem alto potencial para o melhoramento visando à resistência a diversas doenças que provocam perdas expressivas em cultivos comerciais de maracujá-azedo (Passiflora edulis Sims). Seus frutos são comestíveis e têm elevado valor comercial como fruta fresca. Dessa forma, esse estudo teve como objetivo analisar as características físicas e químicas dos frutos e determinar, em condições de campo, o rendimento de dez acessos de $P$. nitida procedentes de estados e/ou de diferentes tipos fitofisionômicos das regiões Centro - Norte do Brasil. O experimento foi conduzido na Embrapa Cerrados, localizada em Planaltina, Distrito Federal. Os acessos avaliados foram coletados em Manaus-AM, de capoeira; no Núcleo Rural São José - DF, de chapada e de vereda; no Vale do Amanhecer - DF, de vereda; Jardim Botânico-DF, de Cerrado Stricto Sensu; em Silvânia-GO, de mata ciliar e de chapada; em Itiquira - MT, de Cerrado Stricto Sensu; em Alto Paraíso-GO, de chapada, e em Natividade-TO, de chapada. O delineamento estatístico foi em blocos casualizados, com quatro repetições e três plantas úteis por repetição. As plantas foram propagadas por estacas enraizadas de cada acesso e conduzidas em espaldeiras verticais de 1,80 metro de altura, com irrigação por gotejamento. As avaliações foram feitas durante as colheitas de 2006 e 2007. O acesso do Vale do Amanhecer apresentou o melhor rendimento de frutos. Este acesso pode ser usado no programa de melhoramento visando à inserção de $P$. nitida no mercado. Também foi possível observar que as fontes provenientes do Cerrado têm características físicas mais desejáveis, produzindo frutos maiores e com melhor rendimento em polpa. Por outro lado, o acesso do Amazonas teve a menor espessura da casca, característica desejável para o mercado de frutas naturais.

Termos para indexação: maracujá-suspiro, características agronômicas, origem geográfica, tipos fitofisionômicos.

\section{PHYSICAL AND CHEMICAL CHARACTERISTICS AND YIELD OF Passiflora nitida Kunth ACCESSIONS FROM NORTH AND CENTRAL REGIONS OF BRAZIL}

ABSTRACT - The passion fruit (Passiflora nitida Kunth) is wild specie widely distributed in national territory. It has high potential for plant breeding aiming at resistance to several diseases that cause expressive losses in plantations of commercial passion fruit (Passiflora edulis Sims). Its fruits are edible and have a high commercial value as fresh fruit. Thus, this study aimed to analyze the physical and chemical characteristics of fruits and to determine under field conditions, the yield of ten accessions of $P$. nitida from different States and phytofisionomic types of north and central regions of Brazil. This work was carried out at Embrapa Cerrados, located at Planaltina, Federal District. The accessions evaluated were collected in Manaus-AM, from secondary rainforest; in Núcleo Rural São José - DF, from plateau and vereda; in Vale do Amanhecer DF, from vereda; in Botanic garden - DF, from Cerrado Stricto sensu; in Silvânia - GO, from riparian forest and plateau; in Itiquira - MT, from Cerrado Stricto sensu; in Alto Paraíso - GO, from plateau; in Natividade -TO, from plateau. The statistic design was randomized block with four repetitions and tree useful plants. Plants were propagated by stem-rooted cuttings of each access and carried out on vertical espalier system of 1.80 meters high with dripping irrigation. The evaluations were made during the harvesting of 2006 and 2007. The access from Vale do Amanhecer, presented the best fruits yield. This access might be used in an improvement program aiming the insertion of $P$. nitida fruit in the market. It was also possible to observe that sources proceeding from the Brazilian Savannas have more desirable physical characteristics, producing bigger fruits and with more pulp yield. On the other hand, the access from Amazonas showed small peel thickness, a desirable characteristic to natural fruit market.

Index terms: Passiflora nitida Kunth, agronomic characteristics, geographical origin, phytophysiognomic types.

${ }^{1}$ (Trabalho 179-09). Recebido em:04-08-2009. Aceito para publicação em 12-01-2010. Apoio financeiro: CNPq, CAPES e Embrapa Cerrados.

${ }_{2}^{2}$ Pesquisadores da Embrapa Cerrados, BR 020, Km 18, Caixa Postal 08223, 73010-970. Planaltina-DF. E-mail: junqueir@cpac.embrapa.br, ffaleiro@cpac.embrapa.br, fideles@cpac.embrapa.br. 


\section{INTRODUÇÃO}

O maracujá-suspiro (Passiflora nitida Kunth) pertence ao grupo dos maracujás doces e apresenta um grande potencial para a utilização per si, embora ainda não existam cultivos comerciais e predomine a atividade extrativista. $\mathrm{O}$ aproveitamento alimentar desta espécie ainda é muito restrito aos estados da região Norte do País que, até então, era considerada o maior centro de diversidade da espécie no Brasil. Apesar de o mercado ser ainda incipiente, frutos desta espécie vêm sendo comercializados em feiras livres na região Norte e Centro-Oeste por até $\mathrm{R} \$ 5,00 / \mathrm{kg}$. Com a descoberta de $P$. nitida vegetando vigorosamente em diversos tipos fitofisionômicos do Cerrado Central, com peculiares características fenotípicas, surgiram melhores perspectivas para a sua exploração econômica. Os acessos provenientes do Cerrado são, notadamente, mais vigorosos e possuem frutos maiores quando comparados àqueles originários do Norte. Oliveira e Ruggiero (2005) já haviam relatado o potencial desta espécie para comércio in natura e estudaram sua aceitabilidade entre os consumidores, obtendo resultados satisfatórios.

As características físico-químicas do maracujá são de grande importância para o melhoramento genético dessa frutífera, pois permitem avaliar as propriedades organolépticas e de sabor dos frutos, garantindo a sua qualidade para o mercado in natura ou para a indústria. Além disso, muitas doenças, como a bacteriose (Xanthomonas axonopodis pv. passiflorae), a antracnose (Colletotrichum gloeosporioides), a virose do endurecimento do fruto (Cowpea Aphid Born Mosaic Virus $C A B M V$ ou Passionfruit Woodness Virus - PWV) e o nematoide das galhas (Meloidogyne spp.), têm sido limitantes ao cultivo do maracujazeiro, podendo provocar perdas totais (JUNQUEIRA et al., 2004). Dessa forma, atualmente, busca-se, por meio de pesquisas, selecionar genótipos de maracujazeiro mais produtivos e mais resistentes a doenças por meio de cruzamentos convencionais das seleções comerciais com as espécies silvestres (hibridação interespecífica) ou cultivadas (hibridação intraespecífica), por seleção massal e recorrente ou, até mesmo, pela exploração de novas espécies de potencial econômico. O maracujá-suspiro é uma espécie interessante, tanto para ser incorporada a programas de melhoramento, em função da resistência à bacteriose e antracnose nos frutos e tolerância à virose (JUNQUEIRA et al., 2005), importantes doenças do maracujazeiro azedo e doce, quanto para a utilização per si.

Com relação à produtividade, alguns estudos e estimativas já foram realizados e citados por Pereira (1998). Entretanto, esses valores podem variar muito, de acordo com a procedência do acesso estudado, tendo em vista a grande variabilidade intraespecífica existente em $P$. nitida, conforme já foi constatado por Junqueira et al. (2007).

Considerando o potencial comercial de frutos de $P$. nitida, objetivou-se analisar as características físico-químicas e a produtividade de dez acessos de $P$. nitida, procedentes de diferentes estados e tipos fitofisionômicos do Centro-Norte do Brasil, sob condições de cultivo.

\section{MATERIAL E MÉTODOS}

O experimento foi conduzido no campo experimental da Embrapa Cerrados, em delineamento em blocos ao acaso, com quatro repetições e três plantas úteis por parcela, sendo que as plantas de cada acesso eram clones. As mudas foram obtidas por estaquia e, após o enraizamento e brotação em casa de vegetação, foram plantadas em campo, em outubro de 2005. Os acessos estudados encontram-se dispostos na Tabela 1.

As plantas foram adubadas e irrigadas por gotejamento de acordo com as recomendações para a cultura do maracujazeiro (BORGES et al., 2002). A polinização entre os clones para a produção dos frutos foi natural. As avaliações foram realizadas durante toda a safra de 2006 e 2007, sendo os frutos de cada planta colhidos ao atingir coloração integralmente amarelada, contabilizados e pesados, obtendo-se a massa média de frutos por acesso e o número médio de frutos por planta. Para o cálculo da produtividade por hectare, foi realizada uma estimativa considerando o espaçamento de 2,5 metros entre fileiras e entre plantas, totalizando 1.600 plantas/ha.

As análises físico-químicas foram realizadas no Laboratório de Fruticultura e Pós-Colheita da Embrapa Cerrados (CPAC), em Planaltina-DF. Utilizaram-se 28 frutos de cada um dos acessos estudados. Deve-se salientar que todas as plantas estudadas de cada acesso eram clones e que foram coletados frutos em todas as plantas para a análise físico-química.

As análises foram iniciadas 24 horas após a colheita. A princípio, foram realizadas as avaliações físicas de cada fruto, medindo-se a massa, os diâmetros longitudinal e transversal e o comprimento do pedúnculo. Os frutos foram despolpados posteriormente com o uso de peneira plástica. Após este procedimento, determinaram-se a massa da 
polpa acrescida das sementes, a massa da polpa, a massa da semente, o volume de suco e a espessura da casca.

As avaliações de diâmetro do fruto e espessura da casca foram realizadas com auxílio de um paquímetro digital. Para a medida da espessura da casca, foi adotado, como padrão, o sentido transversal do fruto. As massas de fruto, polpa acrescida de sementes, polpa e sementes foram obtidas utilizandose de balança analítica. O volume do suco, em mililitros, foi obtido com o auxílio de uma proveta. As sementes foram colocadas em copos descartáveis de $50 \mathrm{ml} \mathrm{e}$, em seguida, pesadas em balança. A massa da casca foi determinada pela diferença entre a massa da polpa acrescida das sementes e a massa do fruto.

Em seguida, procederam-se as análises químicas. Foram avaliados a acidez titulável (AT), o teor de sólidos solúveis (SS) e o pH. A AT, expressa em percentagem de ácido cítrico, foi determinada pela titulação com hidróxido de sódio $(\mathrm{NaOH})$, a $0,2 \mathrm{~N}$, em $6 \mathrm{ml}$ de suco, usando-se duas gotas de fenolftaleína a $1 \%$ como indicador, até atingir coloração rósea, segundo metodologia preconizada por Pregnolatto e Pregnolatto (1985). Após a titulação, anotou-se o volume gasto de $\mathrm{NaOH}$ para cada amostra e foi determinada a acidez titulável de acordo com a AOAC (1990). Para o maracujá, o ácido orgânico predominante é o ácido cítrico (CHITARRA; CHITARRA, 1990).

Foi realizada a análise de variância, e as médias das características dos diferentes acessos foram comparadas pelo teste de Tukey, a 5\% de probabilidade, utilizando-se do programa estatístico SISVAR (FERREIRA, 2000).

\section{RESULTADOS E DISCUSSÃO}

Houve diferenças significativas, pelo teste $\mathrm{F}$, a $5 \%$ de probabilidade, entre os acessos, para todas as características, com exceção do comprimento do pedúnculo e SST. Com base na comparação entre médias das características físico-químicas de frutos dos dez acessos de P. nitida (Tabela 2), observam-se grandes diferenças entre os acessos, ressaltando a grande diversidade intraespecífica. Essa variabilidade genética da espécie $P$. nitida já havia sido relatada por Junqueira et al. (2007) com base em marcadores moleculares.

Analisando-se as características massa de fruto e massa de polpa acrescida de sementes, massa de polpa sem as sementes e massa de sementes, o acesso "Vale do Amanhecer" apresentou as maiores médias de $135,17 \mathrm{~g}, 42,42 \mathrm{~g}, 21,29 \mathrm{~g}$ e $21,13 \mathrm{~g}$, respectivamente, sendo que, para a característica massa de fruto, não diferiu do acesso "N.R. São José - Chapada" $(128,49 \mathrm{~g})$. As menores médias para tais características foram constatadas no acesso "Manaus 1" (49,92g, 16,55g, 5,93g e $10,62 \mathrm{~g}$, respectivamente). A massa média de frutos encontrada por Pereira (1998) em P. nitida acesso "Manaus" variou entre 23,49 g e 53,02 g, sendo a média de $35,78 \mathrm{~g}$. De acordo com Oliveira \& Ruggiero (1998), os frutos de P. nitida possuem média de massa de $45 \mathrm{~g}$. Constatou-se, portanto, que os acessos procedentes do Cerrado produzem frutos consideravelmente mais pesados do que aqueles procedentes do Amazonas. Possivelmente, haja alguma influência genética nesse aspecto, tendo em vista que Junqueira et al. (2007) constataram, por meio de RAPD, grande variabilidade genética entre os acessos do Cerrado e da Amazônia, que ficaram agrupados separadamente.

A menor espessura de casca foi constatada no acesso "Manaus 1" $(1,00 \mathrm{~cm})$. Em relação aos diâmetros longitudinais e transversais, o acesso "N.R. São José - Chapada" apresentou a maior média $(8,14 \mathrm{~cm})$, porém não diferiu estatisticamente dos acessos “N.R. São José - Vereda" (7,25cm), "Vale do Amanhecer" (7,75cm), "Jardim Botânico" (7,00cm), "Silvânia - Mata Ciliar" (7,25cm), "Silvânia-Chapada" (7,75cm) e "Natividade" (7,33cm). O menor diâmetro longitudinal foi observado no acesso "Manaus 1" (5,25cm), que também apresentou o menor diâmetro transversal $(5,00 \mathrm{~cm})$. Para esta última característica, o maior valor também foi constatado em "N.R. São José - Chapada" $(8,15 \mathrm{~cm})$, que não diferiu de "N.R São José - Vereda" $(7,50 \mathrm{~cm})$ e "Vale do Amanhecer" (7,75cm).

Os maiores valores de $\mathrm{pH}$ foram observados nos acessos "N.R. São José - Chapada" $(4,32)$, "N.R. São José - Vereda" (4,30), "Jardim Botânico" $(4,36)$, "Silvânia - Mata Ciliar" (4,31) e "Silvânia Chapada" $(4,33)$, porém não diferiram de "Vale do Amanhecer" $(4,04)$ e "Alto Paraíso" $(4,08)$. O menor pH foi constatado no acesso "Manaus 1" $(3,61)$.

Em relação à acidez titulável, o maior valor foi observado no acesso "Manaus 1 " $(0,10 \%)$. Os menores valores foram encontrados nos acessos "N.R. São José - Vereda" (0,04\%), "Jardim Botânico" $(0,04 \%)$ e "Silvânia - Mata Ciliar" (0,04\%), entretanto não diferiram de "N.R. São José - Chapada" (0,05\%), "Vale do Amanhecer" (0,05\%), "Silvânia - Chapada" (0,05\%) e "Alto Paraíso" (0,07\%).

Quanto ao número de frutos produzidos por planta e à produtividade, os resultados mostraram diferenças entre os acessos, para ambos os parâmetros. Para essa característica, o acesso "Vale do Amanhecer" também proporcionou o maior valor 
$(38,75)$, porém não diferiu dos demais, sendo superior apenas ao acesso "Itiquira 1 " $(3,79)$ e "Alto Paraíso" $(5,67)$ (Tabela 3).

Com relação à produtividade, a maior média também foi constatada no acesso "Vale do Amanhecer" $(8,65 \mathrm{t} / \mathrm{ha})$, procedente do Cerrado. A menor produtividade foi observada nos acessos "Jardim Botânico" (1,69 t/ha), "Silvânia - Mata Ciliar" (1,57 t/ha), "Itiquira 1" (0,58 t/ha), "Alto Paraíso" (0,76 t/ha) e "Manaus 1" (2,23t/ha) (Tabela 3). O valor reduzido de produtividade do acesso amazônico é função principalmente da menor massa dos frutos, já que o número de frutos produzidos não foi diferente dos acessos de maior produtividade.

É possível observar que os acessos procedentes do Cerrado possuem características físicas mais desejáveis, produzindo frutos maiores e com maior quantidade de polpa. Por outro lado, o acesso procedente do Amazonas proporcionou menor espessura de casca, característica desejável para o mercado de frutas in natura. Maiores estudos, especialmente envolvendo hibridações interespecíficas, são importantes a fim de se obter um material genético promissor para o mercado. Deve-se salientar que outras características agronômicas, como resistência a doenças, devem também ser analisadas nos diferentes acessos. Além disso, em virtude do potencial para consumo in natura, testes sensoriais devem ser realizados. Considerando a variabilidade genética observada, têm-se boas perspectivas para trabalhos de seleção e melhoramento genético da espécie visando ao desenvolvimento de variedades para o mercado de frutas in natura.

TABELA 1 - Relação de acessos de Passiflora nitida analisados na Embrapa Cerrados. Embrapa Cerrados, Planaltina-DF, 2008.

\begin{tabular}{|c|c|c|c|c|}
\hline Número & Acesso / Tipo fitofisionômico & Estado & Bioma & Código \\
\hline 1 & “N. R. São José” (Chapada) & DF & Cerrado & CPAC MJ-01-01 \\
\hline 2 & “N. R. São José” (Vereda) & DF & Cerrado & CPAC MJ-01-02 \\
\hline 3 & "Vale do Amanhecer" (Vereda) & DF & Cerrado & CPAC MJ-01-03 \\
\hline 4 & $\begin{array}{c}\text { "Jardim Botânico" } \\
\text { (Cerrado Stricto Sensu) }\end{array}$ & DF & Cerrado & CPAC MJ-01-04 \\
\hline 5 & "Silvânia" (Mata Ciliar) & GO & Cerrado & CPAC MJ-01-05 \\
\hline 6 & “Silvânia” (Chapada) & GO & Cerrado & CPAC MJ-01-06 \\
\hline 7 & $\begin{array}{c}\text { "Itiquira 1" } \\
\text { (Cerrado Stricto Sensu) }\end{array}$ & MT & Cerrado & CPAC MJ-01-07 \\
\hline 8 & $\begin{array}{c}\text { "Alto Paraíso" (Chapada) } \\
\text { "Natividade" }\end{array}$ & GO & Cerrado & CPAC MJ-01-09 \\
\hline 10 & $\begin{array}{c}\text { (Comunidade do Brejão) } \\
\text { (Chapada) }\end{array}$ & TO & Cerrado & CPAC MJ-01-13 \\
\hline 11 & "Manaus 1" (Capoeira) & AM & Amazônia & CPAC MJ-01-15 \\
\hline
\end{tabular}


敢

要

节

क्षे

क्⿹

ê

电

है

D.

응

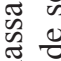

政

(

Ẽ

은

홍

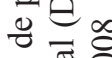

敬

ơ

额

2 은

है 言

क :

氜

西

词

을 总

흥 호

용

문

홍

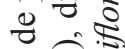

论

$\exists \circ 0$

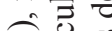

现害

욜

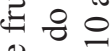

$\because$ 궁

踏

沓 蒙

क ज्ञ

莺它定

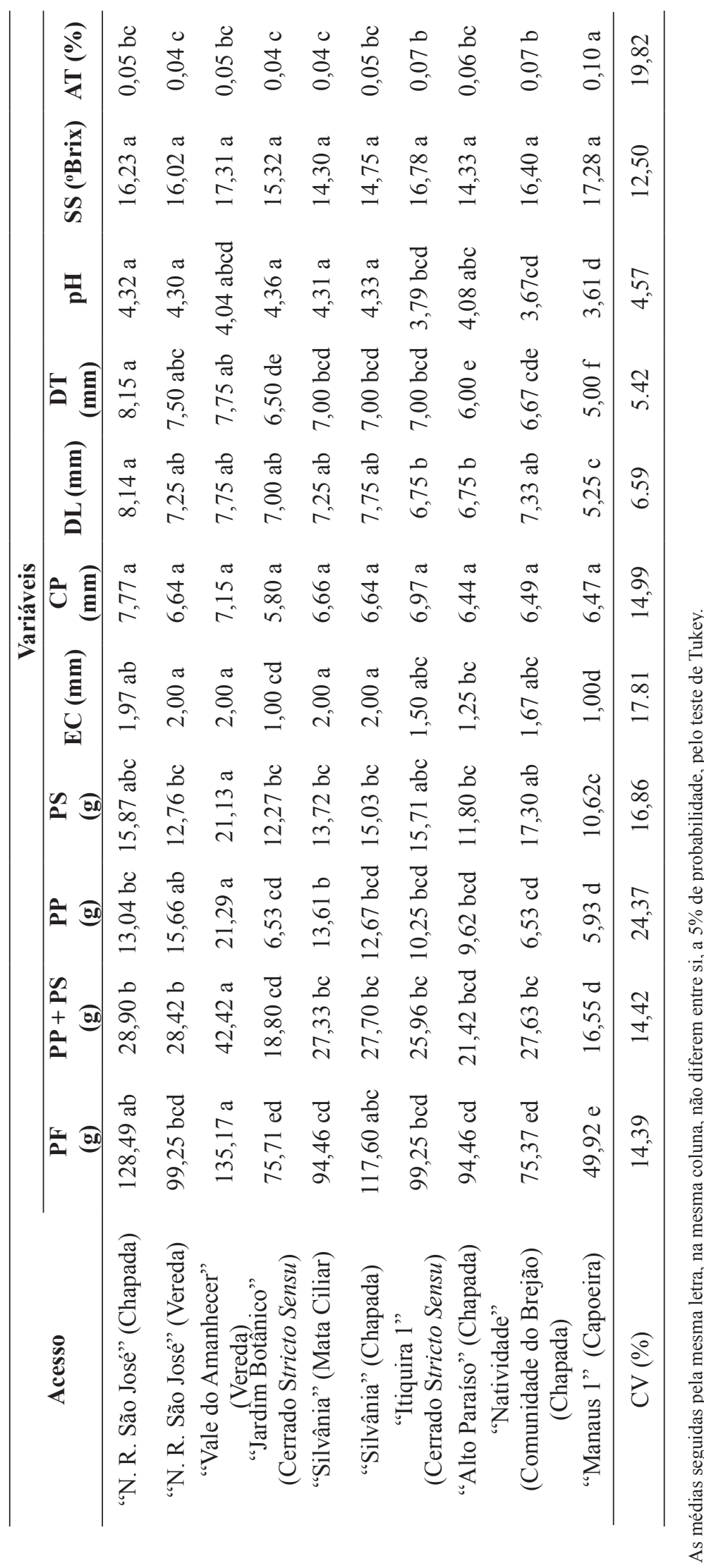


TABELA 3 - Médias de número de frutos por planta (NF) e produtividade, avaliados em em 10 acessos de Passiflora nitida. Embrapa Cerrados, Planaltina-DF, 2008.

\begin{tabular}{ccc}
\hline & \multicolumn{2}{c}{ Variáveis } \\
\cline { 2 - 3 } Acesso & NF & $\begin{array}{c}\text { Produtividade } \\
\text { (t/ha) }\end{array}$ \\
\hline "N. R. São José" (Chapada) - DF & $13,75 \mathrm{ab}$ & $2,94 \mathrm{ab}$ \\
N. R. São José"(Vereda) - DF & $20,33 \mathrm{ab}$ & $3,47 \mathrm{ab}$ \\
"Vale do Amanhecer" (Vereda) - DF & $38,75 \mathrm{a}$ & $8,65 \mathrm{a}$ \\
"Jardim Botânico" (Cerrado Stricto Sensu) - DF & $13,54 \mathrm{ab}$ & $1,69 \mathrm{~b}$ \\
"Silvânia" (Mata Ciliar) - GO & $10,25 \mathrm{ab}$ & $1,57 \mathrm{~b}$ \\
"Silvânia" (Chapada) - GO & $18,50 \mathrm{ab}$ & $3,47 \mathrm{ab}$ \\
"Itiquira 1" (Cerrado Stricto Sensu) - MT & $3,79 \mathrm{~b}$ & $0,58 \mathrm{~b}$ \\
"Alto Paraíso" (Chapada) - GO & $5,67 \mathrm{~b}$ & $0,76 \mathrm{~b}$ \\
"Natividade" (Comunidade do Brejão) (Chapada) - TO & $25,04 \mathrm{ab}$ & $2,94 \mathrm{ab}$ \\
"Manaus 1" (Capoeira) - AM & $28,46 \mathrm{ab}$ & $2,23 \mathrm{~b}$
\end{tabular}

As médias seguidas pela mesma letra, na mesma coluna, não diferem entre si, a 5\% de probabilidade, pelo teste de Tukey.

\section{CONCLUSÕES}

Os resultados evidenciam alta variabilidade genética dos acessos de Passiflora nitida para várias características físico-química de frutos e produtividade. Acessos procedentes do Cerrado possuem características físicas mais desejáveis, produzindo frutos maiores e com maior quantidade de polpa. $\mathrm{O}$ acesso "Vale do Amanhecer" apresenta-se altamente promissor em relação às características estudadas, devendo, portanto, ser inserido em um programa de melhoramento visando ao desenvolvimento de variedades e à inserção da espécie Passiflora nitida no mercado de frutas in natura.

\section{REFERÊNCIAS}

ASSOCIATIN OF OFFICIAL ANALYTICAL CHEMISTS - AOAC. Official methods of analysis of the Associatin of Official Analytical Chemists. $15^{\text {th }}$ Ed. Arlington, 1990. v. 1, p. 685-1213.

BORGES, A.L.; RAIJ, B.; MAGALHÃES, A.F. de J.; BERNARDI, A. C. de C.; LIMA, A. de A. Nutrição mineral, calagem e adubação do maracujazeiro irrigado. Cruz das Almas: Embrapa Mandioca e Fruticultura, 2002. 8 p. (Circular Técnica, 50).

Chitarra, M. I. F.; ChitarRA, A. B. Póscolheita de frutos e hortaliças: fisiologia e manuseio. Lavras: ESAL/Fundação de Apoio ao Ensino, Pesquisa e Extensão, 1990. 293 p.
FERREIRA, D. F. Análise estatística por meio do SISVAR (Sistema para Análise devariância) para Windows versão 4.0. In: REUNIÃO ANUAL DA REGIÃO BRASILEIRA DASOCIEDADE INTERNACIONAL DE BIOMETRIA, 45., 2000, São Carlos. Anais...São Carlos: UFSCar, 2000. p. 255-258.

JUNQUEIRA, K.P.; FALEIRO, F.G.; RAMOS, J.D.; BELLON, G.; JUNQUEIRA, N.T.V.; BRAGA, M.F. Variabilidade genética de acessos de maracujásuspiro com base em marcadores moleculares. Revista Brasileira de Fruticultura, Jaboticabal, v.29, n.3, p.571-575, 2007.

JUNQUEIRA, N. T. V.; ANJOS, J. R. N.; JUNQUEIRA, L. P.; SHARMA, R. D. Doenças do maracujá-doce. In: MANICA, I.; BRANCHER, A.; SANZONOWICZ, C.; ICUMA, I. M.; AGUIAR, J. L. P.; AZEVEDO, J. A.; VASCONCELLOS, M. A. S.; JUNQUEIRA, N. T. V. Maracujá-doce: tecnologia de produção e pós-colheita. Porto Alegre: Ed. Cinco Continentes, 2004. p. 113-144.

JUNQUEIRA, N. T. V.; BRAGA, M. F.; FALEIRO, F. G.; PEIXOTO, J. R.; BERNACCI, L. C. Potencial de espécies silvestres de maracujazeiro como fonte de resistência a doenças. In: FALEIRO, F. G., JUNQUEIRA, N. T. V.; BRAGA, M. F. Maracujá: germoplasma e melhoramento genético. Planaltina: Embrapa Cerrados, 2005. p. 81-106. 
OLIVEIRA, J. C. de; RUGGIERO, C. Aspectos sobre o melhoramento do maracujazeiro amarelo. In: SIMPÓSIO BRASILEIRO SOBRE A CULTURA DO MARACUJAZEIRO, 5., 1998, Jaboticabal. Anais... Jaboticabal: FUNEP, 1998. p. 291-310.

OLIVEIRA, J. C. de; RUGGIERO, C. Espécies de maracujá com potencial agronômico. In: FALEIRO, F. G.; JUNQUEIRA, N. T. V.; BRAGA, M. F. Maracujá: germoplasma e melhoramento genético. Planaltina: Embrapa Cerrados, 2005. p. 143-158.
PEREIRA, M. C. N. Fenologia, Produção e Conservação de Frutos de Passiflora nitida H. B. K. nas condições de Jaboticabal - SP. 74 f. Dissertação (Mestrado) - Faculdade de Ciências Agrárias e Veterinárias, Universidade Estadual Paulista. Jaboticabal, 1998.

PREGNOLLATTO, W.; PREGNOLLATTO, N. P. Normas analíticas do Instituto Adolfo Lutz. 3. ed. São Paulo: Instituto Adolfo Lutz, 1985. v. 1, p. 26. 